\title{
A Study of Opiate, Opiate Metabolites and Antihistamines in Urine after Consumption of Cold Syrups by LC-MS/MS
}

\author{
Yao-Te Yen *, Yin-Jue Chang, Pin-Jung Lai, Chi-Lun Chang, Ting-Yueh Chen and \\ San-Chong Chyueh
}

Department of Forensic Science, Investigation Bureau, Ministry of Justice, Xindian District, New Taipei City 23149, Taiwan; b98605015@ntu.edu.tw (Y.-J.C.); r02625039@ntu.edu.tw (P.-J.L.); b98605019@ntu.edu.tw (C.-L.C.); r96524028@ntu.edu.tw (T.-Y.C.); m33096@mjib.gov.tw (S.-C.C.)

* Correspondence: d05223113@ntu.edu.tw; Tel.: +886-2-2911-2241 (ext. 3714)

Received: 20 January 2020; Accepted: 20 February 2020; Published: 21 February 2020

\begin{abstract}
Studying the origin of opiate and/or opiate metabolites in individual urine specimens after consumption of cold syrups is vital for patients, doctors, and law enforcement. A rapid liquid chromatography-tandem mass spectrometry method using "dilute-and-shoot" analysis without the need for extraction, hydrolysis and/or derivatization has been developed and validated. The approach provides linear ranges of $2.5-1000 \mathrm{ng} \mathrm{mL}^{-1}$ for 6-acetylmorphine, codeine, chlorpheniramine, and carbinoxamine, $2.5-800 \mathrm{ng} \mathrm{mL}^{-1}$ for morphine and morphine-3- $\beta$-D-glucuronide, and $2.5-600 \mathrm{ng}$ $\mathrm{mL}^{-1}$ for morphine-6- $\beta$-D-glucuronide and codeine-6- $\beta$-D-glucuronide, with excellent correlation coefficients $\left(\mathrm{R}^{2}>0.995\right)$ and matrix effects $(<5 \%)$. Urine samples collected from the ten participants orally administered cold syrups were analyzed. The results concluded that participants consuming codeine-containing cold syrups did not routinely pass urine tests for opiates, and their morphine-codeine concentration ratios $(\mathrm{M} / \mathrm{C})$ were not always $<1$. In addition, the distribution map of the clinical total concentration of the sum of morphine and codeine against the antihistamines (chlorpheniramine or carbinoxamine) were plotted for discrimination of people who used cold syrups. The 15 real cases have been studied by using $\mathrm{M} / \mathrm{C}$ rule, cutoff value, and distribution map, further revealing a potential approach to determine opiate metabolite in urine originating from cold syrups.
\end{abstract}

Keywords: codeine; morphine; heroin; chlorpheniramine; carbinoxamine; cold syrups

\section{Introduction}

Opiate metabolites usually refer to the metabolites of morphine, codeine, and heroin. Morphine and codeine are natural substances present in poppies, whereas heroin is a semisynthetic product derived from morphine. Heroin, considered one of the most serious drugs abused worldwide, has led to numerous deaths-approximately 15,482 in 2017 [1]. In forensic science, several analytical methods, including gas chromatography-mass spectrometry (GC-MS) [2,3], GC-tandem MS (GC-MS/MS) [4,5], and liquid chromatography-mass spectrometry (LC-MS/MS) [6,7], have been adapted for the identification of heroin, other opiates, and their metabolites.

In humans, heroin and its byproduct 6-acetylcodeine are metabolized to morphine, 6-acetylmorphine (6-AM), morphine-3- $\beta$-D-glucuronide (M3G), morphine-6- $\beta$-D-glucuronide (M6G), codeine and codeine-6- $\beta$-D-glucuronide (C6G) $[8,9]$. However, some natural foods and medicines, such as cold syrups that contain certain amounts of codeine, can produce opiate metabolites in urine. Therefore, a person suspected of abusing heroin might defend himself by claiming to have taken medicines or foods containing codeine or morphine, which is referred to as the "poppy seed 
defense" [10,11]. As an important biomarker, 6-AM has been used for determining if a person has consumed heroin [12]. Unfortunately, owing to the short half-life of 6-AM, it can not be detected in urine samples especially after heroin consumption for $8 \mathrm{~h}[13,14]$. In 1988, the US Department of Defense increased the confirmation cutoff value of morphine from 300 to $2000 \mathrm{ng} \mathrm{mL}^{-1}$ to reduce the probability of misidentification, but this led to a much lower positive confirmation rate $[15,16]$. In 2014, a marker for street heroin, acetylated-thebaine-4-metabolite glucuronide (ATM4G), was suggested [17]. However, ATM4G is unavailable commercially, limiting its practicality as a marker. In addition, the oral administration of poppy seeds and widely available poppy seed products were investigated $[10,18,19]$, and they found that a morphine-codeine concentration ratio of below $1(<1)$ was a suitable index for the determination of foods containing poppy seeds [20,21]. However, few studies have examined the consumption of cold syrups, mainly because food containing opiate-ingredients caused more social problems than cold syrups in western countries [22-25]. Whereas, the opposite was true in Asia.

Codeine and antihistamines are usually mixed in cold syrups due to their pain relief and cough suppression properties in Asia [26]. Therefore, a person suspected of abusing heroin might defend himself by attributing a failed urine drug test to having taken cold syrups. To confirm this defense, ten participants were orally administered three brands of cold syrups available in pharmacy stores in Taiwan. The concentrations of opiates (morphine and codeine), opiate metabolites (M3G, M6G, C6G, and 6-AM), and the two antihistamines (chlorpheniramine or carbinoxamine) in urine samples from participants who were administered the cold syrups and the concentrations of the same compounds in samples from 15 people suspected of abusing opiates were determined through an LC-MS/MS approach. The ratios of the total concentrations of morphine and codeine, as well as distribution of the total concentration of the sum of morphine and codeine against chlorpheniramine or carbinoxamine, were all investigated to study opiate, opiate metabolites, and chlorpheniramine/carbinoxamine in urine after consumption of cold syrups.

\section{Results and Discussion}

\subsection{Method Development and Assay Validation}

Table S1 summarized the transitions, fragments, and collision energies for M3G, morphine- $\mathrm{d}_{6}$, morphine, M6G, C6G, codeine- $\mathrm{d}_{6}$, codeine, 6-AM, chlorpheniramine- $\mathrm{d}_{6}$, chlorpheniramine, and carbinoxamine optimized with an Agilent MassHunter optimizer. Figure S1 showed an example of the successful separation of each analyte $\left(1000 \mathrm{ng} \mathrm{mL}^{-1}\right)$ under the optimized conditions using LC-MS/MS in extracted-ion mode, and the retention times of the analytes were in the range of 2.8-10 $\mathrm{min}$.

The correlation coefficients $\left(\mathrm{R}^{2}\right)$, calibrated linear ranges, limits of detections (LODs), carryovers, accuracies, and coefficients of variation (CV\% values) for morphine, 6-AM, M3G, M6G, codeine, C6G, chlorpheniramine, and carbinoxamine were summarized in Table 1. All the calibration curves of the analytes were linear $\left(R^{2}>0.995\right)$ for quantitation in different linear ranges. The calibrated linear ranges were $2.5-800 \mathrm{ng} \mathrm{mL}^{-1}$ for morphine and M3G, 2.5-600 $\mathrm{ng} \mathrm{mL}^{-1}$ for M6G and $\mathrm{C} 6 \mathrm{G}$, and 2.5-1000 $\mathrm{ng} \mathrm{mL}^{-1}$ for 6-AM, codeine, chlorpheniramine, and carbinoxamine. The LODs of the analytes were $0.2-1.3 \mathrm{ng} \mathrm{mL}^{-1}$, confirming that the LC-MS/MS approach was sensitive for the quantitation of these analytes in urine samples. The linear ranges of morphine, M3G, M6G, and C6G, which contain phenol or glucuronide groups, resulting in $\mathrm{pH}$-dependent ionization efficiency, were narrower than those of 6-AM, codeine, chlorpheniramine, and carbinoxamine. The LOD of morphine was higher than those of the other analytes, mainly because electrospray formation was hampered attributed to a lower content of organic modifier (water/acetonitrile $=83 / 17, v / v)$ at the retention time $(3.7 \mathrm{~min}$ ). The selectivity of this method and the influence of endogenous compounds were assessed using blank urine samples. As shown in Figure S2, unexpected interferences were not observed in the chromatograms, but obvious signals of the internal standards (ISs) and the analytes at their LODs were visible, confirming the excellent selectivity and sensitivity of the method [27-30]. 
Table 1. Internal standards, correlation coefficients, calibrated linear ranges, limits of detections (LODs), carryovers, accuracies, and precisions with these analytes.

\begin{tabular}{|c|c|c|c|c|c|c|c|c|}
\hline Compound & Morphine & 6-AM & M3G & M6G & Codeine & C6G & Chlorpheniramine & Carbinoxamine \\
\hline $\begin{array}{c}\text { Internal standard } \\
R^{2}\end{array}$ & $\begin{array}{c}\text { Morphine- } \mathrm{d}_{6} \\
0.998\end{array}$ & $\begin{array}{c}\text { Morphine- } \mathrm{d}_{6} \\
0.998\end{array}$ & $\begin{array}{l}\text { Morphine- } \mathrm{d}_{6} \\
0.997\end{array}$ & $\begin{array}{l}\text { Morphine- } \mathrm{d}_{6} \\
0.999\end{array}$ & $\begin{array}{l}\text { Codeine- } \mathrm{d}_{6} \\
0.997\end{array}$ & $\begin{array}{c}\text { Codeine- } \mathrm{d}_{6} \\
0.998\end{array}$ & $\begin{array}{c}\text { Chlorpheniramine- } \mathrm{d}_{6} \\
0.999\end{array}$ & $\begin{array}{c}\text { Chlorpheniramine- } \mathrm{d}_{6} \\
0.999\end{array}$ \\
\hline Linear range $\left(\mathrm{ng} \mathrm{mL}^{-1}\right)$ & $2.5-800$ & $2.5-1000$ & $2.5-800$ & $2.5-600$ & $2.5-1000$ & $2.5-600$ & $2.5-1000$ & $2.5-1000$ \\
\hline $\operatorname{LOD}\left(\mathrm{ng} \mathrm{mL}^{-1}\right)$ & 1.3 & 0.5 & 0.4 & 0.5 & 0.6 & 0.2 & 0.2 & 0.3 \\
\hline Carryover (\%) & -0.03 & 0.03 & 0.01 & 0.01 & -0.01 & -0.03 & 0.01 & -0.01 \\
\hline \multicolumn{9}{|l|}{ Accuracy for QC (\%) ${ }^{a}$} \\
\hline \multicolumn{9}{|l|}{ Intraday $(n=3)$} \\
\hline QC-Low & 89.6 & 88.3 & 89.4 & 86.4 & 89.2 & 83.8 & 83.2 & 83.1 \\
\hline QC-Medium & 102.3 & 112.2 & 92.4 & 88.2 & 103.5 & 84.2 & 97.7 & 98.4 \\
\hline QC-High & 108.3 & 110.0 & 99.4 & 93.1 & 102.5 & 88.5 & 100.6 & 101.2 \\
\hline \multicolumn{9}{|l|}{ Interday $(n=3)$} \\
\hline QC-Low & 88.8 & 88.5 & 86.3 & 85.8 & 87.8 & 84.1 & 85.3 & 85.3 \\
\hline QC-Medium & 98.9 & 104.6 & 92.7 & 90.2 & 100.9 & 89.0 & 98.0 & 98.4 \\
\hline QC-High & 104.0 & 103.9 & 100.4 & 95.8 & 101.2 & 96.2 & 100.2 & 100.4 \\
\hline \multicolumn{9}{|l|}{ Precision for QC (\%) ${ }^{b}$} \\
\hline \multicolumn{9}{|l|}{ Intraday $(n=3)$} \\
\hline QC-Low & 3.6 & 3.0 & 3.2 & 2.8 & 1.1 & 1.7 & 0.6 & 0.2 \\
\hline QC-Medium & 1.0 & 0.2 & 0.8 & 3.3 & 0.4 & 2.1 & 0.2 & 0.8 \\
\hline QC-High & 1.8 & 0.9 & 1.7 & 3.1 & 1.3 & 1.3 & 0.7 & 1.5 \\
\hline \multicolumn{9}{|l|}{ Interday $(n=3)$} \\
\hline QC-Low & 4.2 & 2.9 & 4.1 & 3.2 & 1.8 & 2.5 & 3.9 & 4.0 \\
\hline QC-Medium & 4.6 & 6.2 & 3.5 & 8.3 & 2.3 & 7.6 & 1.4 & 1.7 \\
\hline QC-High & 3.7 & 4.5 & 1.7 & 4.5 & 1.6 & 6.2 & 0.9 & 1.1 \\
\hline
\end{tabular}

${ }^{a}$ Accuracy is assessed by determining the recovery percentage of these analytes. ${ }^{b}$ Precision is assessed by determining the coefficients of variation (CV \% value) of these analytes. 
Carryover was tested with the use of equation (1). The carryover indices of all analytes were within $1 \%$, indicating the absence of significant carryover between the analyses of the working solutions at the highest and lowest tested concentrations [31]. The intraday assay precision values at low, moderate, and high concentrations of the testing analytes were $0.2 \%-3.6 \%, 0.2 \%-3.3 \%$, and $0.7 \%-3.1 \%$, respectively. The interday assay precision values at low, moderate, and high concentrations were $1.8 \%-4.2 \%, 1.4 \%-8.3 \%$, and $0.9 \%-6.2 \%$ at 0,7 , and 14 days, respectively. The intraday and interday assay accuracies were in the range of $83.1 \%$ to $112.2 \%$ and $84.1 \%$ to $104.6 \%$ (i.e., within the $\pm 20 \%$ maximum acceptance criteria) [32].

Table S2 listed the slopes and matrix effects (MEs) of the urine matrix calibration curves obtained using "dilute-and-shoot" analysis without extraction, hydrolysis and/or derivatization. The MEs were assessed by analyzing the analytes spiked into five individual blank urine samples and pure solvent according to a previously reported procedure [33,34]. Morphine, 6-AM, M6G, codeine, C6G, and carbinoxamine demonstrated MEs of $0 \%$ to $8.7 \%$, implying that the urine matrix did not significantly affect the ionization of these analytes (within $-15 \%$ to $15 \%$ ) $[33,35]$. However, the urine matrix significantly enhanced the signals of M3G and chlorpheniramine (MEs > 15\%). The highest matrix effect (approximately 32\%) for M3G was observed, mainly because that higher amounts of polar constituents from urine matrix were co-eluted with M3G for ion enhancement at a short retention time (2.8 $\mathrm{min}$ ) in a higher content of aqueous modifier (water/acetonitrile $=91 / 9, v / v)$ [36-38]. Thus, to reduce this effect, a matrix-match method was used for quantitation. As expected, a high precision $(<5 \%)$ of MEs was achieved in the five individual blank urine samples. The interference effects were assessed by analyzing our targets when mixed with high concentrations of the interferents. The results revealed biases in the range of $-4 \%$ to $9 \%$ within $\pm 20 \%$ of the target concentration [39]. The dilution integrity was assessed for 2-, 10- and 20-fold dilutions as shown in Table S3. The results revealed that the accuracies were in the range of $94.0 \%$ to $106.9 \%$, which are within the acceptable variation of $\pm 15 \%$ of the nominal concentration, and precisions were in the range of $0.2 \%$ to $5.2 \%$ in the three replicates. Table S4 showed the excellent stabilities of the analytes during storage, the concentrations of all the analytes were stable within a variation of $\pm 10 \%$ over a period of 28 days, indicating that urine samples stored at $4{ }^{\circ} \mathrm{C}$ prior to analysis were suitable for these assays.

\subsection{Clinical Trials Study}

Cold syrups were orally administered to ten participants following the suggested use on packaging ( 4.8 or $5 \mathrm{mg}$ of codeine phosphate in each dose, three times a day for three days). Three different cold syrups were tested, and the average analyte concentrations and the calculated total concentration of morphine or codeine in the urine samples from the ten participants were displayed in Figure 1. For the samples (Consrine, ssBuron, and Pabron), the average concentrations of C6G (419-1190, 624-1476, and 358-1406 ng mL $\left.{ }^{-1}\right)$ and M3G (177-353, 326-508, and 114-263 $\left.\mathrm{ng} \mathrm{mL}^{-1}\right)$ were obviously higher than those of codeine (249-940, 307-944, and 226-728 $\mathrm{ng} \mathrm{mL}^{-1}$ ) and morphine (7.6-130, 8.7-17, and 8.2-13 $\mathrm{ng} \mathrm{mL} \mathrm{m}^{-1}$ ), respectively, during the trial period of $0-66 \mathrm{~h}$, indicating that opiate-glucuronides were the major metabolites of the opiate. When syrup consumption was terminated, the concentrations of the opiate and the opiate metabolites decreased quickly. On the other hand, chlorpheniramine or carbinoxamine was still detectable after 84-132 h of administration, and thus these compounds can be used as markers to determine the use of cold syrups. The changes in opiate concentrations as a function of time were slightly different for the three formulations due to differential lifestyles and metabolic rates of the participants, the times at which the urine samples were collected, and the small number of samples. A time interval of cold syrups taken by participants for their last dose that day until the next day's use was approximately $12 \mathrm{~h}$, which caused decreasing concentrations of each metabolite in the urine samples under $30-48 \mathrm{~h}$ of administration.

The details of the total concentrations of codeine or morphine in the urine samples of all participants were displayed in Figure 2. During oral administration of the cold syrups (Consrine, ssBuron, and Pabron), 14.4, 24.4, and 5.6\% of the urine samples (13 of 90, 22 of 90, and 5 of 90) revealed concentrations 
of morphine (calculated based on the free form of morphine, M3G, and M6G) higher than $300 \mathrm{ng} \mathrm{mL}^{-1}$, but all the concentrations were under $2000 \mathrm{ng} \mathrm{mL}^{-1}$. For codeine (calculated based on the free form of codeine and C6G), 48.9, 60.0, and 46.7\% of the urine samples (44 of 90, 54 of 90, and 42 of 90 ) revealed concentrations higher than $300 \mathrm{ng} \mathrm{mL}^{-1}$. Furthermore, $4.4,11.1$, and $8.9 \%$ of the urine samples $(4 \mathrm{of}$ 90, 10 of 90, and 8 of 90) showed codeine concentrations higher than $2000 \mathrm{ng} \mathrm{mL}^{-1}$. The ratios of the total concentrations of morphine and codeine $(\mathrm{M} / \mathrm{C})$ in the urine samples of all the participants were displayed in Figure 3. The results showed that the $\mathrm{M} / \mathrm{C}$ values were under 1 during the trial period of $0-66 \mathrm{~h}$, which was consistent with the rule of $\mathrm{M} / \mathrm{C}<1$ [21]. Unfortunately, after $72 \mathrm{~h}$ of administration, the $\mathrm{M} / \mathrm{C}$ values increased gradually, eventually violating the rule of $\mathrm{M} / \mathrm{C}<1$, attributed to that the metabolite rate of morphine was slower than that of codeine [40].

(A)

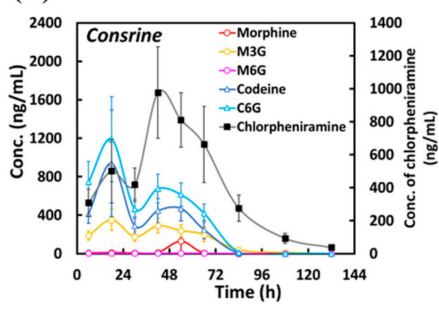

(B)

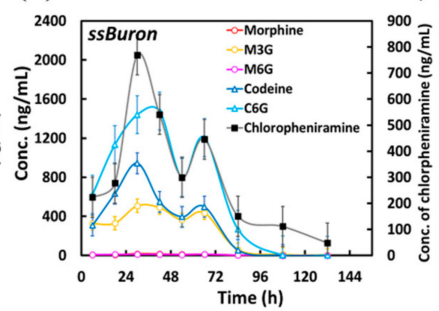

(C)

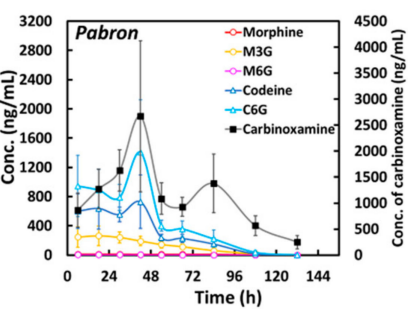

Figure 1. Clinical average concentrations of opiate, opiate metabolites, and antihistamines (chlorpheniramine or carbinoxamine) in the urine samples of the ten participants collecting from different times under oral administration of cold syrups (A) Consrine, (B) ssBuron, and (C) Pabron based on the suggested use ( 4.8 or $5 \mathrm{mg}$ codeine phosphate for each use) from the provider.
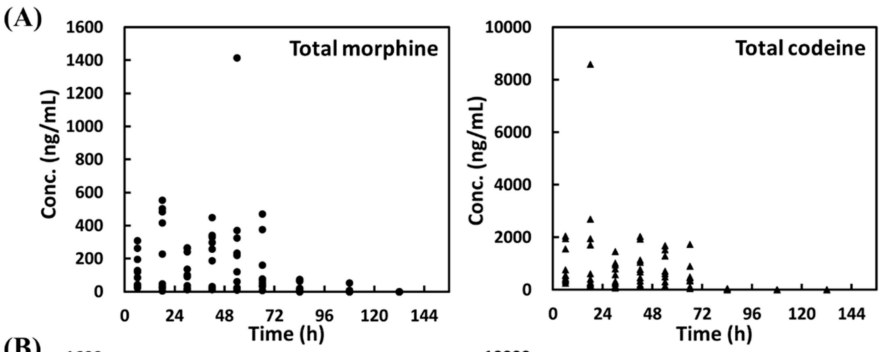

(B)
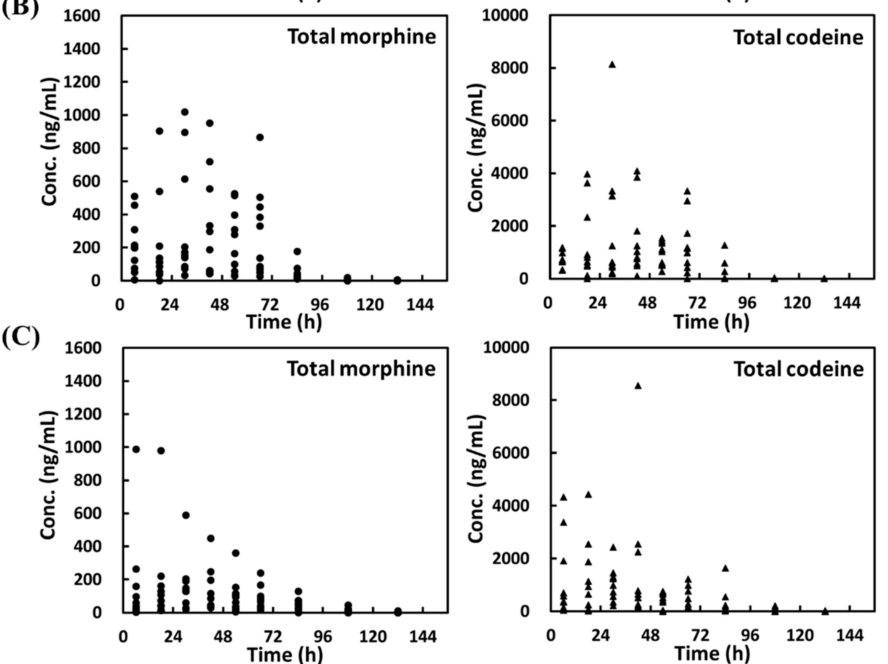

Figure 2. Total concentrations of morphine (left) and codeine (right) in the clinical urine samples from the ten participants collected at different times following oral administration of cold syrups based on the suggested use ( 4.8 or $5 \mathrm{mg}$ codeine phosphate in each dose) described by the manufacturer (A) Consrine, (B) ssBuron, and (C) Pabron). Total morphine refers to the total concentration of morphine calculated from the free form of morphine, $\mathrm{M} 3 \mathrm{G}$, and M6G in the urine. Total codeine refers to the total concentration of codeine calculated from the free form of codeine and $\mathrm{C} 6 \mathrm{G}$ in the urine. 
(A)

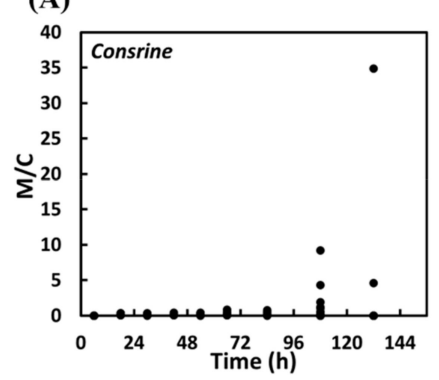

(B)

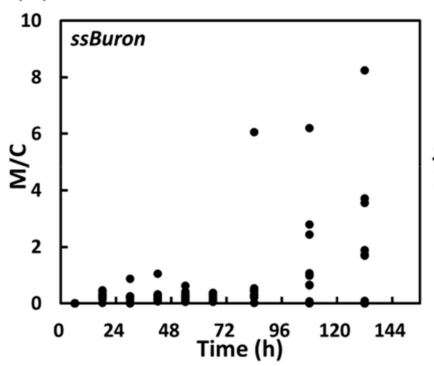

(C)

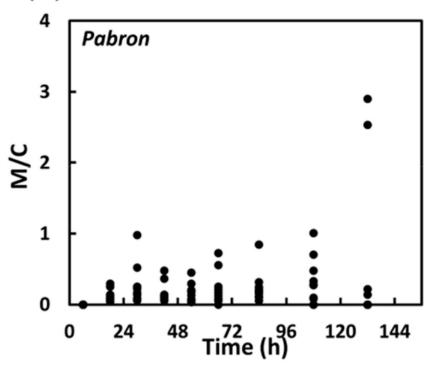

Figure 3. Ratios of the clinical concentrations of total morphine and total codeine $(M / C)$ in the urine samples from the ten participants orally administered the cold syrups (A) Consrine, (B) ssBuron, and (C) Pabron.

Table 2 listed the concentrations of the 6-AM, opiate, opiate metabolites, and $\mathrm{M} / \mathrm{C}$ values in samples from 15 real cases. A worldwide-accepted biomarker, 6-AM, is used to determine suspects for their heroin consumption. The case 1, 6, 13, and 15 found 6-AM in their urine samples, confirming those suspects for heroin use. However, 6-AM was not detected in other cases, mainly because those suspects probably did not consume heroin, or the short life of 6-AM was metabolized to morphine in bodies after heroin consumption. In addition, the $\mathrm{M} / \mathrm{C}$ values and the concentrations of morphine or codeine from samples 1-8 were over 5 and over the cutoff value of $300 \mathrm{ng} \mathrm{mL}^{-1}$ (for Taiwan), respectively. Thus, we can deduce that these people did abuse heroin [20]. Interestingly, because chlorpheniramine was detected in cases $9-15$, we can infer that these suspects consumed cold syrups or other chlorpheniramine-containing medicines. The M/C values from samples 9 and 10 were both within 1 . As for sample 11 , codeine or its metabolites were not detected, thus its $M / C$ value referred to as infinity was close to those of clinical trial results during the trial period of 108-132 h, due to morphine being eliminated more slowly than codeine in the body [40]. The three cases (case 9-11) passing opiate urine test were not prosecuted because of their concentrations of opiate metabolites under the cutoff value ( $300 \mathrm{ng} \mathrm{mL}^{-1}$ ). On the other hand, the cases $12-15$ with their $\mathrm{M} / \mathrm{C}$ values over 3 as well as their concentrations of opiate metabolites over the cutoff value were all prosecuted. Based on our practical experience, cold syrups or other morphine/codeine-containing medicines were likely consumed to mask the illegal abuse of heroin, allowing the "poppy seed defense" for suspects in cases 12-15.

Table 2. Concentrations (ng $\mathrm{mL}^{-1}$ ) and concentration ratios of opiate, opiate metabolites, and antihistamines in urine samples from 15 people suspected of heroin abuse.

\begin{tabular}{cccccccccc}
\hline Case No. & Morphine & 6-AM & M3G & M6G & Codeine & C6G & Chlo. & Carb. & $\mathbf{M}^{\mathbf{b}}$ \\
\hline 1 & 63 & 81 & N.D. ${ }^{\mathbf{c}}$ & 1104 & 3.0 & 16 & N.D. & N.D. & 62 \\
2 & 53 & N.D. & 14 & 990 & 81 & 4.1 & N.D. & N.D. & 8 \\
3 & 73 & N.D. & 3116 & 45 & 23 & 132 & N.D. & N.D. & 19 \\
$4^{\text {a }}$ & $>16000$ & N.D. & $>16000$ & 3527 & 3718 & 2454 & N.D. & N.D. & $>5$ \\
$5^{\text {a }}$ & 11422 & N.D. & $>16000$ & 1365 & 1519 & 2024 & N.D. & N.D. & $>8$ \\
6 & 1963 & 480 & 14339 & 747 & 792 & 1416 & N.D. & N.D. & 7 \\
7 & 505 & N.D. & 11051 & 127 & 92 & 198 & N.D. & N.D. & 34 \\
$8^{\text {a }}$ & 3686 & N.D. & 510 & $>12000$ & 291 & 273 & N.D. & N.D. & $>25$ \\
9 & N.D. & N.D. & N.D. & N.D. & N.D. & 5.6 & 38 & N.D. & 0 \\
10 & N.D. & N.D. & 11 & N.D. & 8.9 & 10 & 8.7 & N.D. & 0.4 \\
11 & 2.7 & N.D. & N.D. & N.D. & N.D. & N.D. & 337 & N.D. & $\infty$ \\
12 & 208 & N.D. & 41 & 7182 & 111 & 89 & 21 & N.D. & 28 \\
$13^{\text {a }}$ & $>16000$ & 12 & 9388 & $>12000$ & 1836 & 3037 & 4.3 & N.D. & $>8$ \\
$14^{\text {a }}$ & $>16000$ & N.D. & 3793 & $>12000$ & 3925 & 2683 & 122 & N.D. & $>5$ \\
$15^{\text {a }}$ & $>16000$ & 6722 & $>16000$ & $>12000$ & 7029 & 10838 & 63 & N.D. & $>3$ \\
\hline
\end{tabular}

a Parts of analytes are over validated concentrations. ${ }^{b}$ The ratios of the total concentrations of morphine and codeine $(\mathrm{M} / \mathrm{C}) .{ }^{\mathrm{c}}$ N.D: no detection. ${ }^{\mathrm{d}}$ The ratio being referred to as infinity. 
Furthermore, the distribution of total concentration of the sum of morphine and codeine against chlorpheniramine or carbinoxamine obtained from clinical trials, as well as those from samples 9-15 were mapped in Figure 4A,B. The results showed that distributions of samples 9-11 were overlapped with those determined in the clinical trials, confirming the suspects in the three cases consumed cold syrups containing codeine and chlorpheniramine. Conversely, samples 12-15 have no overlapping with those acquired from clinical trials, further revealing the four suspects consumed heroin and cold syrups. Finally, the suspects in cases 1-8 and 12-15 were prosecuted and thus judged in a court in Taiwan to have consumed heroin. Therefore, this distribution map showed the potential for determining opiate and opiate metabolites derived from cold syrups in urine samples. However, it was noted that for cancer patients, morphine was used for the treatment of cancer pain [41,42]. It was still difficult to discriminate against the opiate metabolites in urine from heroin or morphine without detection of 6-AM, but patients can provide certificates of diagnosis and prescriptions from doctors to prove their legal use.

(A)

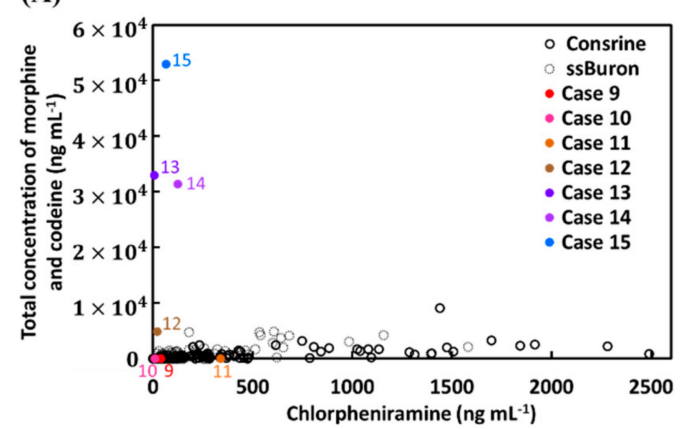

(B)

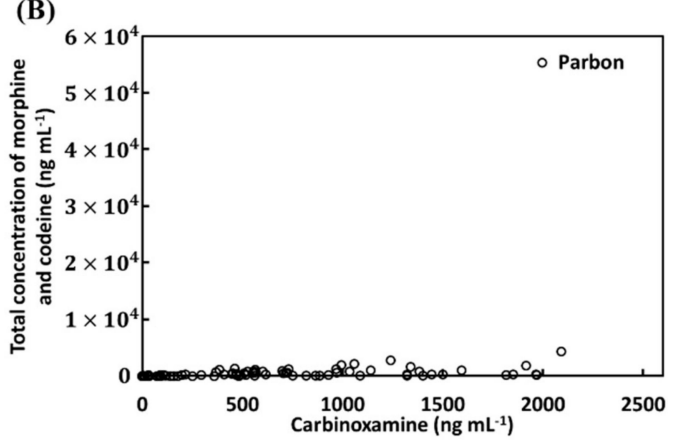

Figure 4. Distribution map of the total concentration of the sum of morphine and codeine against (A) chlorpheniramine and (B) carbinoxamine obtained from ten participants orally administered the cold syrups of Consrine, ssBuron, and Pabron, as well as those from seven people suspected of heroin abuse in cases 9-15.

\section{Materials and Methods}

\subsection{Chemicals}

Carbinoxamine, chlorpheniramine, and chlorpheniramine- $\mathrm{d}_{6}$ were purchased from TRC (North York, Canada). Individual solutions of 6-AM, 7-aminonitrazepam, 7-aminonimetazepam, amphetamine, benzoylecgonine, C6G, codeine, codeine- $\mathrm{d}_{6}$, ketamine, methamphetamine, mephedrone, 4-methylephedrine, 3,4-methylenedioxymethamphetamine hydrochloride, M3G, M6G, morphine, morphine- $\mathrm{d}_{6}$, and norketamine (each with a concentration of $1 \mathrm{mg} \mathrm{mL}^{-1}$ ) were purchased from Cerilliant (Round Rock, TX, USA). Three brands of cold syrups (Consrine, ssBuron, and Pabron) manufactured in Taiwan were purchased from local pharmacies. Consrine contains codeine phosphate $(0.48 \mathrm{mg}$ $\left.\mathrm{mL}^{-1}\right)$, chlorpheniramine $\left(0.25 \mathrm{mg} \mathrm{mL}^{-1}\right)$, dl-methyl ephedrine $\mathrm{HCl}\left(1.6 \mathrm{mg} \mathrm{mL}^{-1}\right)$, and glycyrrhizic acid $\left(0.25 \mathrm{mg} \mathrm{mL}^{-1}\right)$, ssBuron contains codeine phosphate $\left(0.5 \mathrm{mg} \mathrm{mL}^{-1}\right)$, guaifenesin $\left(3.33 \mathrm{mg} \mathrm{mL}^{-1}\right)$, chlorpheniramine maleate $\left(0.14 \mathrm{mg} \mathrm{mL}^{-1}\right)$, and caffeine $\left(1.33 \mathrm{mg} \mathrm{mL}^{-1}\right)$, Pabron contains codeine phosphate $\left(0.48 \mathrm{mg} \mathrm{mL}^{-1}\right)$, dl-methyl ephedrine $\mathrm{HCl}\left(2.5 \mathrm{mg} \mathrm{mL}^{-1}\right)$, and carbinoxamine maleate $\left(0.4 \mathrm{mg} \mathrm{mL}^{-1}\right)$. Formic acid and methanol (high-performance LC grade) ( $\geq 98 \%$ ) were purchased from J.T. Baker (Pittsburgh, PA, USA). Ultrapure water $(18.2 \mathrm{~m} \Omega \cdot \mathrm{cm})$ obtained from a Milli-Q ultrapure water system (Millipore, Billerica, MA, USA) was used in this study. 


\subsection{Urine Samples}

\subsubsection{Clinical Trial Urine Samples}

Ten participants ( 5 male and 5 female) aged 22-56 years with a mean weight of $67 \mathrm{~kg}$ were administered $10 \mathrm{~mL}$ of cold syrup after each meal three times a day for three days (72 h) according to suggested use described by the manufacturer. Urine samples were collected before and after oral administration of the cold syrup (i.e., before administration and 6, 18, 30, 42, 54, 66, 84, 108, and $132 \mathrm{~h}$ after administration), and the samples were stored at $4{ }^{\circ} \mathrm{C}$ until analysis. All participants agreed this study and gave their informed consents before experiments. All experiments were performed in compliance with the ICH E6 Guidance for Industry (E6 Good Clinical Practice: Consolidated Guidance) and approved by the Joint Institutional Review Board of Taiwan (Certificate of Approval JIRB No: 18-S-004-1).

\subsubsection{Urine Samples from Real Cases}

Urine samples from 15 suspects in real cases involving opiate abuse were acquired from the Taipei District Prosecutors Office in Taiwan and were used for analysis. All urine samples were stored at 4 ${ }^{\circ} \mathrm{C}$ until analysis. According to the Court's Judgments, 12 of the suspects were convicted of heroin consumption, and the others were found innocent.

\subsection{Preparation of Solutions}

All standard solutions $\left(1 \mathrm{mg} \mathrm{mL}^{-1}\right)$ were diluted with methanol to prepare stock solutions: $100 \mathrm{ng} \mathrm{mL}^{-1}$ for morphine, morphine- $\mathrm{d}_{6}, 6$-AM, codeine, codeine- $\mathrm{d}_{6}$, chlorpheniramine, carbinoxamine, and chlorpheniramine- $\mathrm{d}_{6}, 1000 \mathrm{ng} \mathrm{mL}^{-1}$ for $\mathrm{M} 3 \mathrm{G}, \mathrm{M6G}$, and C6G. These stock solutions were then used to optimize the transitions, fragmentors, and collision energies for these analytes using an LC-MS/MS approach. Two mixed stock solutions containing morphine, 6-AM, M3G, M6G, codeine, C6G, carbinoxamine, and chlorpheniramine (each $1000 \mathrm{ng} \mathrm{mL}{ }^{-1}$ ) were prepared in a 1:1 $(v / v)$ mixture of methanol and water for either calibration or quality control (QC). The working solutions used for calibration were prepared by diluting the mixed stock solutions with a 1:1 $(v / v)$ mixture of methanol and water to concentrations of 2.5, 5, 10, 40, 80, 200, 400, 600, 800, and $1000 \mathrm{ng} \mathrm{mL} \mathrm{m}^{-1}$. A stock internal standard mixed solution of morphine- $\mathrm{d}_{6}$, codeine- $\mathrm{d}_{6}$, and chlorpheniramine- $\mathrm{d}_{6}$ were prepared with each component at a concentration of $100 \mathrm{ng} \mathrm{mL} \mathrm{m} \mathrm{in}^{-1}$ 1:1 $(v / v)$ mixture of methanol and water. Similarly, QC solutions from low to high concentrations were prepared by diluting the other mixed stock solution with a 1:1 $(v / v)$ mixture of methanol and water to concentrations of 20, 200, and $600 \mathrm{ng} \mathrm{mL}^{-1}$ for morphine and M3G, 20, 80, and $400 \mathrm{ng}$ $\mathrm{mL}^{-1}$ for M6G and C6G, and 20, 400, and $800 \mathrm{ng} \mathrm{mL}^{-1}$ for codeine, 6-AM, carbinoxamine, and chlorpheniramine. For selectivity assessment, a mixed solution of morphine, 6-AM, M3G, M6G, codeine, C6G, carbinoxamine, and chlorpheniramine in a 1:1 (v/v) mixture of methanol and water with concentrations of their LOQ was prepared. For dilution integrity assessment, 2-, 10-, and 20-fold of low, medium, and high QC concentrations of morphine, 6-AM, M3G, M6G, codeine, C6G, carbinoxamine, and chlorpheniramine in a 1:1 $(v / v)$ mixture of methanol and water with were separately prepared. The samples for assessing interferents were prepared by mixing morphine, 6-AM, M3G, M6G, codeine, C6G, carbinoxamine, and chlorpheniramine (each $20 \mathrm{ng} \mathrm{mL}^{-1}$ ) with likely interferents, including methamphetamine, amphetamine, ketamine, norketamine, 3,4-methylenedioxymethamphetamine, mephedrone, 4-methylephedrine, benzoylecgonine, 7-aminonitrazepam, and 7-aminonimetazepam (each $1000 \mathrm{ng} \mathrm{mL}^{-1}$ ) in a 1:1 (v/v) mixture of methanol and water.

\subsection{Apparatus}

The LC-MS/MS system consisted of an autosampler (Agilent G7167A, Santa Clara, USA), a binary pump (Agilent G7112B, Santa Clara, USA), a separation column $(3.0 \times 100 \mathrm{~mm}, 2.7 \mu \mathrm{m}$, Poroshell 120SB-AQ Agilent, Santa Clara, USA), and a mass spectrometer (Agilent 6470 QqQ-MS, Santa Clara, 
USA), and the urine samples were assessed in electrospray ionization mode. Mass spectrometry was performed using multiple reaction monitoring (MRM) mode to analyze 8 species, including morphine, 6-AM, M3G, M6G, codeine, C6G, chlorpheniramine, and carbinoxamine. Morphine- $\mathrm{d}_{6}$, codeine- $\mathrm{d}_{6}$, and chlorpheniramine- $\mathrm{d}_{6}$ were used as internal standards. The LC-MS/MS system was operated under the following conditions: drying gas temperature of $280{ }^{\circ} \mathrm{C}$, flow rate of $8 \mathrm{~L} \mathrm{~min}{ }^{-1}$, and nebulizer pressure of 45 psi. Two product ions were obtained for each analyte, and their MRM ion ratios calculated from the peak areas of the two product ions were used for qualitative evaluation, the fragment with the greater area was used for quantitation. The mobile phase was a mixture of solvent A ( $0.1 \%$ formic acid aqueous solution) and solvent B (100\% acetonitrile) at a flow rate of $0.3 \mathrm{~mL} \mathrm{~min}{ }^{-1}$. The gradient program was set as follows: $0-0.5 \mathrm{~min}$ (a volume ratio of solvent $\mathrm{A}$ to $\mathrm{B}$ of 97:3), 0.5-3 min (decreasing to 90:10), 3-5 min (decreasing to 70:30), 5-10 $\mathrm{min}$ (decreasing to 50:50), 10-15 min (decreasing to 20:80), 15-17 min (decreasing to 0:100), 17-18 $\mathrm{min}$ (0:100), and 18-28 $\mathrm{min}$ (97:3). The sample was injected using an autosampler, and the injection volume was $5 \mu \mathrm{L}$. The Software (Version B.08.00, Agilent Technologies Inc., 2016) was used for quantitative and qualitative analyses.

\subsection{Method and Validation}

\subsubsection{Analytical Strategy}

According to the guideline of SWGTOX Standard Practices for Method Validation, the US Food and Drug Administration (FDA), and the European Medicines Agency (EMA) Guidelines on Bioanalytical Method $[32,43,44]$, the parameters that must be validated include the dynamic range, LOQ, selectivity, precision, accuracy, carryover effect, matrix effect, interferents, dilution integrity (dilution factor: 2 , 10, and 20), and stability. A rapid "dilute-and-shoot" analytical method was validated and used to determine the concentrations of opiate, opiate metabolites, chlorpheniramine, and carbinoxamine in urine samples from participants that had been orally administered cold syrup and from 15 people suspected of abusing opiates.

\subsubsection{Dynamic Ranges, LOQs, and LODs}

Aliquots $(20 \mu \mathrm{L})$ of the working solution, blank urine $(20 \mu \mathrm{L})$, and mixed IS solution $(20 \mu \mathrm{L})$ were mixed with $940 \mu \mathrm{L}$ of the eluent $(\mathrm{A}: \mathrm{B}=97: 3)$ in 2 -mL vials to prepare the samples for calibration $(n=5)$. A weighted $(1 / x)$ regression model was used to prepare calibration curves based on the peak area ratios of the analytes relative to the ISs. The back-calculated concentrations of the calibrators are within $\pm 15 \%$ of the target values at all points except the LOQ. The lowest concentration of each analyte in the linear range was defined as the LOQ, and at this concentration, the calculated value was within $\pm 20 \%$. In addition, to determine the LOD, the most dilute working solution was diluted 1 to 10 times with a 1:1 $(v / v)$ mixture of methanol and water. Aliquots $(20 \mu \mathrm{L})$ of the aforementioned diluted working solutions, $20 \mu \mathrm{L}$ of blank urine, and $20 \mu \mathrm{L}$ of the mixed IS solution were mixed with $940 \mu \mathrm{L}$ of the eluent (A: B = 97:3) in 2-mL vials to prepare the samples for qualitative analysis. The LOD of each analyte was set as the concentration producing a signal with an intensity 3 times that of the noise $(\mathrm{S} / \mathrm{N}=3, \mathrm{n}=7)$.

\subsubsection{Selectivity}

The selectivity of the analytic method was assessed by comparing the chromatograms of ten lots of blank urine, blank urine spiked with the analytes at their LOQs, and IS-spiked blank urine. Each $20 \mu \mathrm{L}$ of blank urine was mixed with $980 \mu \mathrm{L}$ of the eluent (A: B =97: 3) in 2-mL vials to prepare samples for assessing possible endogenous interferents $(n=10)$. Aliquots $(20 \mu \mathrm{L})$ of a mixture of the analytes at their LOQ and $20 \mu \mathrm{L}$ of blank urine were mixed with $960 \mu \mathrm{L}$ of the eluent $(\mathrm{A}: \mathrm{B}=97: 3)$ in $2-m L$ vials to prepare samples to check the responses of analytes $(n=10)$. Similarly, $20 \mu \mathrm{L}$ of blank urine and $20 \mu \mathrm{L}$ of the IS mixed solution were mixed with $960 \mu \mathrm{L}$ of the eluent $(\mathrm{A}: \mathrm{B}=97: 3)$ in $2-\mathrm{mL}$ vials to prepare samples to check the response of each IS $(n=10)$. 


\subsubsection{Accuracy and Precision}

The recovery percentage from the nominal concentration and $\mathrm{CV} \%$ from interday and intraday assays based on analysis of QC samples $(n=6)$ were used to assess the accuracy and precision of this method. QC samples were prepared by mixing $20 \mu \mathrm{L}$ of QC solutions, $20 \mu \mathrm{L}$ of blank urine, and $20 \mu \mathrm{L}$ of IS mixture solution with $940 \mu \mathrm{L}$ of the eluent $(\mathrm{A}: \mathrm{B}=97: 3)$ in 2-mL vials.

\subsubsection{Carryover}

The carryover was assessed by analyzing the most dilute working solution four times immediately after analyzing the most concentrated working solution three times. The carryover index was calculated as follows [31]:

$$
\text { Carryover index }(\%)=\left(\frac{L_{1}-\frac{L_{3}+L_{4}}{2}}{\frac{H_{2}+H_{3}}{2}-\frac{L_{3}+L_{4}}{2}}\right) \times 100
$$

where $\mathrm{L}_{1}, \mathrm{~L}_{3}$, and $\mathrm{L}_{4}$ are the peak areas of the most dilute working solutions from runs 1,3 , and 4 , respectively, and $\mathrm{H}_{2}$ and $\mathrm{H}_{3}$ are the peak areas of the most concentrated working solutions from runs 2 and 3 , respectively.

\subsubsection{Matrix Effect}

MEs were investigated according to the literature [30,31]. A urine matrix-free sample was prepared by mixing $20 \mu \mathrm{L}$ of the working solution and $20 \mu \mathrm{L}$ of the mixed IS solution with $960 \mu \mathrm{L}$ of eluent ( $\mathrm{A}: \mathrm{B}=97: 3$ ) before analysis. Urine matrix samples were prepared by spiking five $20-\mu \mathrm{L}$ blank urine samples with $20 \mu \mathrm{L}$ of working solution and $20 \mu \mathrm{L}$ of the mixed IS solution and then diluting the samples with $940 \mu \mathrm{L}$ of eluent (A: B =97:3). To assess the ME on each analyte, experiments were performed at calibration levels with five blank urine samples. The MEs were evaluated by comparing the slope of the calibration curve of the matrix standards with that of the calibration curve of the neat standards using the following equation (2) [33,34]:

$$
\operatorname{ME}(\%)=\left(\frac{\text { slope of the urine matrix calibration curve }}{\text { slope of the neat calibration curve }}-1\right) \times 100
$$

\subsubsection{Interferences Study}

Interference samples were prepared by mixing our target analytes with high concentrations (1000 ng mL $\mathrm{m}^{-1}$ ) of likely interferents. These samples were analyzed in three replicates and then quantitatively evaluated for interference effects.

\subsubsection{Dilution Integrity}

Each analyte with 2-, 10-, and 20-fold of QC concentrations in a 1:1 $(v / v)$ mixture of methanol and water were diluted 2-, 10-, and 20-fold using a mixed eluent (A: B = 97:3), separately. Similarly, aliquots $(20 \mu \mathrm{L}$ ) of the dilution sample, $20 \mu \mathrm{L}$ of blank urine, and $20 \mu \mathrm{L}$ of the mixed IS solution were mixed with $940 \mu \mathrm{L}$ of the eluent $(\mathrm{A}: \mathrm{B}=97: 3)$ in 2 -mL vials to prepare the samples $(\mathrm{n}=3)$.

\subsubsection{Stability}

For stability assessment, a mixture containing each analyte at $20 \mathrm{ng} \mathrm{mL}^{-1}$ was analyzed, and it was reanalyzed after $7,14,21$ and 28 days of storage at $4{ }^{\circ} \mathrm{C}$. Aliquots $(20 \mu \mathrm{L})$ of the aforementioned mixture, $20 \mu \mathrm{L}$ of blank urine, and $20 \mu \mathrm{L}$ of mixed IS solution were mixed with $940 \mu \mathrm{L}$ of the eluent (A: $B=97: 3)$ in 2-mL vials to prepare the samples $(n=6)$. 


\subsubsection{Clinical Trials Study}

An established method was applied to determine the concentrations of opiate, opiate metabolites, chlorpheniramine, and carbinoxamine in the urine samples from the ten participants. The ratios of the total concentrations of morphine and codeine were calculated. The clinical urine samples used for analysis were prepared by mixing $20 \mu \mathrm{L}$ of each participant's urine sample and $20 \mu \mathrm{L}$ of IS mixture solution with $960 \mu \mathrm{L}$ of the eluent (A: B = 97:3) in 2-mL vials. Since the concentrations of analytes in urine samples determined through an LC-MS/MS approach in this study were over the highest concentrations of calibration curves, clinical urine sample was then diluted 5-, 10-, and 20-fold using a mixed eluent ( $\mathrm{A}: \mathrm{B}=97: 3$ ) before mixing with $20 \mu \mathrm{L}$ of IS mixture solution with $960 \mu \mathrm{L}$ of the eluent $(\mathrm{A}: \mathrm{B}=97: 3)$ in $2-\mathrm{mL}$ vials.

\subsubsection{Real Case Study}

The concentrations of opiate, opiate metabolites, chlorpheniramine, and carbinoxamine in urine samples from 15 people suspected of heroin abuse were determined. Similar to the analysis of the clinical samples, the ratios of the total concentrations of morphine and codeine were calculated. The urine samples for analysis were separately prepared following a procedure similar to that used for the clinical samples. The real urine samples used for analysis were prepared by mixing $20 \mu \mathrm{L}$ of each suspect's urine sample and $20 \mu \mathrm{L}$ of IS mixture solution with $960 \mu \mathrm{L}$ of the eluent (A: B =97:3) in $2-\mathrm{mL}$ vials. While the concentrations of analytes in urine samples determined through the established method in this study were over the highest concentrations of calibration curves, real urine samples were then diluted 5-, 10-, and 20-fold using a mixed eluent (A: B = 97:3) before mixing with $20 \mu \mathrm{L}$ of IS mixture solution with $960 \mu \mathrm{L}$ of the eluent $(\mathrm{A}: \mathrm{B}=97: 3)$ in $2-\mathrm{mL}$ vials.

\section{Conclusions}

A rapid analytic method for the quantitation of opiate, opiate metabolites, and antihistamines (chlorpheniramine and carbinoxamine) in urine through LC-MS/MS was developed and validated. The results of a clinical trial revealed that people consuming cold syrups do not consistently pass opiate urine tests and the samples do not have morphine-codeine concentration ratios $<1$ routinely. The distribution map of the total concentration of the sum of morphine and codeine against chlorpheniramine or carbinoxamine in the urine samples from participants were plotted, respectively, which were used to determine opiate metabolites in urine originated from cold syrups. Samples from fifteen people suspected of heroin abuse were analyzed and validated using $\mathrm{M} / \mathrm{C}$ rule, cutoff value, and distribution map. To the best of our knowledge, this is the first report to discuss the concentrations of antihistamines and to study the distribution of total concentration of the sum of morphine and codeine against an antihistamine derived from cold syrup use.

Supplementary Materials: The following are available online, Table S1: MRM transitions, retention times, and tuning parameters of the analytes, Table S2: Slopes and MEs of urine matrix calibration curves using "dilute-and-shoot" analyses, Table S3: Accuracy and precision for QC in dilution integrity test, Table S4: Stability assessment, Figure S1: Chromatograms of analytes obtained using LC-MS/MS in extracted-ion mode, Figure S2: Chromatograms of ten lots of blank urine and samples spiked with IS or LOQ-analytes in total-ion mode.

Author Contributions: Conceptualization, Y.-T.Y.; Methodology, Y.-T.Y.; Validation, Y.-J.C., P.-J.L., and C.-L.C.; Data curation, Y.-J.C.; Writing-original draft preparation, Y.-T.Y., Y.-J.C., and T.-Y.C.; Supervision, S.-C.C. All authors have read and agreed to the published version of the manuscript.

Funding: We are grateful to the Ministry of Justice, Taiwan, for providing financial support for this study (107-1301-05-17-02).

Acknowledgments: We are grateful to the ten participants involved in this study.

Conflicts of Interest: The authors declare no conflict of interest. 


\section{References}

1. National Drug Overdose Deaths through 2017. Available online: https://d14rmgtrwzf5a.cloudfront.net/sites/ default/files/national_drug_overdose_deaths_through_2017.pdf (accessed on 15 October 2019).

2. Meadway, C.; George, S.; Braithwaite, R. A rapid GC-MS method for the determination of dihydrocodeine, codeine, norcodeine, morphine, normorphine and 6-MAM in urine. Forensic Sci. Int. 2002, 127, 136-141. [CrossRef]

3. Orfanidis, A.; Mastrogianni, O.; Koukou, A.; Psarros, G.; Gika, H.; Theodoridis, G.; Raikos, N. A GC-MS method for the detection and quantitation of ten major drugs of abuse in human hair samples. J. Chromatogr. B 2017, 1047, 141-150. [CrossRef]

4. Polettini, A.; Groppi, A.; Montagna, M. Rapid and highly selective GC/MS/MS detection of heroin and its metabolites in hair. Forensic Sci. Int. 1993, 63, 217-225. [CrossRef]

5. Saad, M.A.A.; Abu-Rumman, A.M.; Mohamed, K.M. A gas chromatography-triple quadrupole mass spectrometry assay for the quantification of opiates in human blood samples. J. Anal. Toxicol. 2018, 43, 188-195. [CrossRef] [PubMed]

6. Chiang, C.-H.; Lee, H.-H.; Chen, B.-H.; Lin, Y.-C.; Chao, Y.-Y.; Huang, Y.-L. Using ambient mass spectrometry and LC-MS/MS for the rapid detection and identification of multiple illicit street drugs. J. Food Drug Anal. 2019, 27, 439-450. [CrossRef] [PubMed]

7. Krotulski, A.J.; Mohr, A.L.A.; Friscia, M.; Logan, B.K. Field detection of drugs of abuse in oral fluid using the Alere $^{\mathrm{TM}}$ DDS $^{\circledR} 2$ Mobile Test System with confirmation by liquid chromatography tandem mass spectrometry (LC-MS/MS). J. Anal. Toxicol. 2018, 42, 170-176. [CrossRef] [PubMed]

8. Milne, R.W.; Nation, R.L.; Somogyi, A.A. The disposition of morphine and its 3- and 6-glucuronide metabolites in humans and animals, and the importance of the metabolites to the pharmacological effects of morphine. Drug Metab. Rev. 1996, 28, 345-472. [CrossRef]

9. Vree, T.B.; Verwey-Van Wissen, C.P. Pharmacokinetics and metabolism of codeine in humans. Biopharm. Drug Dispos. 1992, 13, 445-460. [CrossRef]

10. Smith, M.L.; Nichols, D.C.; Underwood, P.; Fuller, Z.; Moser, M.A.; LoDico, C.; Gorelick, D.A.; Newmeyer, M.N.; Concheiro, M.; Huestis, M.A. Morphine and codeine concentrations in human urine following controlled poppy seeds administration of known opiate content. Forensic Sci. Int. 2014, 241, 87-90. [CrossRef]

11. Lachenmeier, D.W.; Sproll, C.; Musshoff, F. Poppy seed foods and opiate drug testing—where are we today? Drug Monit. 2010, 32, 11-18. [CrossRef]

12. Meadway, C.; George, S.; Braithwaite, R. Opiate concentrations following the ingestion of poppy seed products-Evidence for 'the poppy seed defence'. Forensic Sci. Int. 1998, 96, 29-38. [CrossRef]

13. Dinis-Oliveira, R.J. Metabolism and metabolomics of opiates: A long way of forensic implications to unravel. J. Forensic Leg. Med. 2019, 61, 128-140. [CrossRef] [PubMed]

14. Ellis, A.D.; McGwin, G.; Davis, G.G.; Dye, D.W. Identifying cases of heroin toxicity where 6-acetylmorphine (6-AM) is not detected by toxicological analyses. Forensic Sci. Med. Pathol. 2016, 12, 243-247. [CrossRef] [PubMed]

15. Selavka, C. Poppy seed ingestion as a contributing factor to opiate-positive urinalysis results: The Pacific perspective. J. Forensic Sci. 1991, 36, 685-696. [CrossRef] [PubMed]

16. Fraser, A.D.; Worth, D. Experience with a urine opiate screening and confirmation cutoff of $2000 \mathrm{ng} / \mathrm{mL}$. J. Anal. Toxicol. 1999, 23, 549-551. [CrossRef] [PubMed]

17. Chen, P.; Braithwaite, R.A.; George, C.; Hylands, P.J.; Parkin, M.C.; Smith, N.W.; Kicman, A.T. The poppy seed defense: A novel solution. Drug Test. Anal. 2014, 6, 194-201. [CrossRef]

18. Guo, B.B.; Zhang, Y.Q.; Wang, S.F.; Ding, J.S.; Zhou, W.H. The pharmacokinetics of morphine and codeine in human plasma and urine after oral administration of Qiangli Pipa Syrup. J. Forensic Sci. 2018, 63, 1221-1228. [CrossRef]

19. Samano, K.L.; Clouette, R.E.; Rowland, B.J.; Sample, R.H.B. Concentrations of morphine and codeine in paired oral fluid and urine specimens following ingestion of a poppy seed roll and raw poppy seeds. J. Anal. Toxicol. 2015, 39, 655-661. [CrossRef] 
20. Konstantinova, S.V.; Normann, P.T.; Arnestad, M.; Karinen, R.; Christophersen, A.S.; Mørland, J. Morphine to codeine concentration ratio in blood and urine as a marker of illicit heroin use in forensic autopsy samples. Forensic Sci. Int. 2012, 217, 216-221. [CrossRef]

21. Ceder, G.; Jones, A.W. Concentration ratios of morphine to codeine in blood of impaired drivers as evidence of heroin use and not medication with codeine. Clin. Chem. 2001, 47, 1980-1984. [CrossRef]

22. Schuppener, L.M.; Corliss, R.F. Death due to complications of bowel obstruction following raw poppy seed ingestion. J. Forensic Sci. 2018, 63, 614-618. [CrossRef] [PubMed]

23. Croitoru, M.D.; Fülöp, I.; Irimia-Constantin, M.R.; Varga, E.; Kelemen, H.; Fogarasi, E.; Faliboga, L.M. The risk of using poppy seed tea made from several varieties available on the romanian market. Acta Med. Marisiensis 2017, 63, 62-65. [CrossRef]

24. EFSA Panel on Contaminants in the Food Chain (CONTAM). Scientific opinion on the risks for public health related to the presence of opium alkaloids in poppy seeds. Efsaj 2011, 9, 2405. [CrossRef]

25. López, P.; Pereboom-de Fauw, D.P.K.H.; Mulder, P.P.J.; Spanjer, M.; de Stoppelaar, J.; Mol, H.G.J.; de Nijs, M. Straightforward analytical method to determine opium alkaloids in poppy seeds and bakery products. Food Chem. 2018, 242, 443-450. [CrossRef]

26. Gardiner, S.J.; Chang, A.B.; Marchant, J.M.; Petsky, H.L. Codeine versus placebo for chronic cough in children. Cochrane Database Syst. Rev. 2016, 7, CD011914. [CrossRef]

27. Huang, W.; Qiu, Q.; Chen, M.; Shi, J.; Huang, X.; Kong, Q.; Long, D.; Chen, Z.; Yan, S. Determination of 18 antibiotics in urine using LC-QqQ-MS/MS. J. Chromatogr. B 2019, 1105, 176-183. [CrossRef]

28. Mercolini, L.; Protti, M.; Catapano, M.C.; Rudge, J.; Sberna, A.E. LC-MS/MS and volumetric absorptive microsampling for quantitative bioanalysis of cathinone analogues in dried urine, plasma and oral fluid samples. J. Pharm. Biomed. Anal. 2016, 123, 186-194. [CrossRef]

29. Tan, B.; Yang, A.; Yuan, W.; Li, Y.; Jiang, L.; Jiang, J.; Qiu, F. Simultaneous determination of glipizide and its four hydroxylated metabolites in human urine using LC-MS/MS and its application in urinary phenotype study. J. Pharm. Biomed. Anal. 2017, 139, 179-186. [CrossRef]

30. Kachingwe, B.H.; Uang, Y.S.; Huang, T.J.; Wang, L.H.; Lin, S.J. Development and validation of an LC-MS/MS method for quantification of NC-8 in rat plasma and its application to pharmacokinetic studies. J. Food Drug Anal. 2018, 26, 401-408. [CrossRef]

31. Cao, Z.; Kaleta, E.; Wang, P. Simultaneous quantitation of 78 drugs and metabolites in urine with a dilute-and-shoot LC-MS-MS assay. J. Anal. Toxicol. 2015, 39, 335-346. [CrossRef]

32. Scientific Working Group for Forensic Toxicology. Scientific working group for forensic toxicology (SWGTOX) standard practices for method validation in forensic toxicology. J. Anal. Toxicol. 2013, 37, 452-474. [CrossRef] [PubMed]

33. Kmellar, B.; Fodor, P.; Pareja, L.; Ferrer, C.; Martinez-Uroz, M.A.; Valverde, A.; Fernandez-Alba, A.R. Validation and uncertainty study of a comprehensive list of 160 pesticide residues in multi-class vegetables by liquid chromatography-tandem mass spectrometry. J. Chromatogr. A 2008, 1215, 37-50. [CrossRef] [PubMed]

34. Ferrer, C.; Lozano, A.; Agüera, A.; Girón, A.J.; Fernández-Alba, A. Overcoming matrix effects using the dilution approach in multiresidue methods for fruits and vegetables. J. Chromatogr. A 2011, 1218, 7634-7639. [CrossRef] [PubMed]

35. Shin, Y.; Lee, J.; Lee, J.; Lee, J.; Kim, E.; Liu, K.H.; Lee, H.S.; Kim, J.H. Validation of a multiresidue analysis method for 379 pesticides in human serum using liquid chromatography-tandem mass spectrometry. J. Agric. Food Chem. 2018, 66, 3550-3560. [CrossRef]

36. Kloepfer, A.; Quintana, J.B.; Reemtsma, T. Operational options to reduce matrix effects in liquid chromatography-electrospray ionization-mass spectrometry analysis of aqueous environmental samples. $J$. Chromatogr. A 2005, 1067, 153-160. [CrossRef]

37. Svan, A.; Hedeland, M.; Arvidsson, T.; Pettersson, C.E. The differences in matrix effect between supercritical fluid chromatography and reversed phase liquid chromatography coupled to ESI/MS. Anal. Chim. Acta 2018, 1000, 163-171. [CrossRef]

38. Eeckhaut, A.V.; Lanckmans, K.; Sarre, S.; Smolders, I.; Michotte, Y. Validation of bioanalytical LC-MS/MS assays: Evaluation of matrix effects. J. Chromatogr. B Anal. Technol. Biomed. Life Sci. 2009, 877, 2198-2207. [CrossRef] 
39. Perez, E.R.; Knapp, J.A.; Horn, C.K.; Stillman, S.L.; Evans, J.E.; Arfsten, D.P. Comparison of LC-MS-MS and GC-MS analysis of benzodiazepine compounds included in the drug demand reduction urinalysis program. J. Anal. Toxicol. 2016, 40, 201-207. [CrossRef]

40. Lafolie, P.; Beck, O.; Lin, Z.; Albertioni, F.; Boréus, L. Urine and plasma pharmacokinetics of codeine in healthy volunteers: Implications for drugs-of-abuse testing. J. Anal. Toxicol. 1996, 20, 541-546. [CrossRef]

41. Wiffen, P.; Wee, B.; Moore, R.A. Oral morphine for cancer pain. Cochrane Database Syst. Rev. 2016, 2016, CD003868. [CrossRef]

42. Bandieri, E.; Romero, M.; Ripamonti, C.I.; Artioli, F.; Sichetti, D.; Fanizza, C.; Santini, D.; Cavanna, L.; Melotti, B.; Conte, P.F.; et al. Randomized trial of low-dose morphine versus weak opioids in moderate cancer pain. J. Clin. Oncol. 2016, 34, 436-442. [CrossRef] [PubMed]

43. Gulideline on Bioanalytical Method Validation. Available online: https://www.ema.europa.eu/en/documents/ scientific-guideline/guideline-bioanalytical-method-validation_en.pdf (accessed on 20 June 2018).

44. Bioanalytical Method Validation Guidance for Industry. Available online: https://www.fda.gov/regulatoryinformation/search-fda-guidance-documents/bioanalytical-method-validation-guidance-industry (accessed on 20 June 2018).

Sample Availability: Samples of the compounds are not available from the authors. 